\title{
Standardization of terminology in stereotactic radiosurgery: Report from the Standardization Committee of the International Leksell Gamma Knife Society
}

\author{
Special topic
}

\author{
Michael Torrens, F.R.C.S., ${ }^{1}$ Caroline Chung, M.D., ${ }^{2}$ Hyun-Tai Chung, Ph.D., ${ }^{3}$ Patrick Hanssens, M.D., ${ }^{4}$ \\ David Jaffray, Ph.D., ${ }^{2}$ Andras Kemeny, F.R.C.S., ${ }^{5}$ David Larson, M.D., Ph.D., ${ }^{6}$ Marc LeVivier, M.D. ${ }^{7}$ \\ Christer Lindquist, M.D., Ph.D., ${ }^{8}$ Bodo Lippitz, M.D. ${ }^{8}$ Josef Novotny JR., Ph.D., ${ }^{9}$ Ian Paddick, M.SC., ${ }^{8}$ \\ Dheerendra Prasad, M.D., M.Ch., ${ }^{10}$ and Chung Ping Yu, M.D. ${ }^{11}$
}

${ }^{l}$ Department of Neurosurgery, Hygeia Hospital, Athens, Greece; ${ }^{2}$ Department of Radiation Oncology, University of Toronto, Ontario, Canada; ${ }^{3}$ Department of Neurosurgery, Seoul National University College of Medicine, Seoul, Republic of

Korea: ${ }^{4}$ Gamma Knife Centre, St. Elizabeth Hospital, Tilburg, The Netherlands, ${ }^{5}$ National Centre for Stereotactic Radiosurgery, Royal Hallamshire Hospital, Sheffield, United Kingdom; ${ }^{6}$ Department of Radiation Oncology, University of California, San Francisco, California $;{ }^{7}$ Centre Hospitalier Universitaire Vaudois, Lausanne, Switzerland; ${ }^{8}$ Gamma Knife Department, Cromwell Hospital, London, United Kingdom; ${ }^{9}$ Department of Medical Physics, Na Homolce Hospital, Prague, Czech Republic;

${ }^{10}$ Departments of Radiation Medicine and Neurosurgery, Roswell Park Cancer Institute, Buffalo, New York; and ${ }^{1 I}$ Gamma Knife, Canossa Hospital, Hong Kong, People's Republic of China

Object. This report has been prepared to ensure more uniform reporting of Gamma Knife radiosurgery treatment parameters by identifying areas of controversy, confusion, or imprecision in terminology and recommending standards.

Methods. Several working group discussions supplemented by clarification via email allowed the elaboration of a series of provisional recommendations. These were also discussed in open session at the 16th International Leksell Gamma Knife Society Meeting in Sydney, Australia, in March 2012 and approved subject to certain revisions and the performance of an Internet vote for approval from the whole Society. This ballot was undertaken in September 2012.

Results. The recommendations in relation to volumes are that Gross Target Volume (GTV) should replace Target Volume (TV); Prescrip-

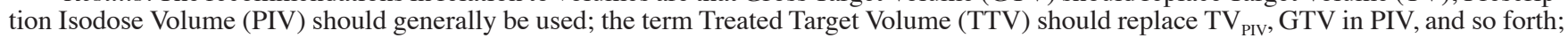
and the Volume of Accepted Tolerance Dose $\left(\mathrm{V}_{\mathrm{ATD}}\right)$ should be used in place of irradiated volume. For dose prescription and measurement, the prescription dose should be supplemented by the Absorbed Dose, or $\mathrm{D}_{\mathrm{v} \%}$ (for example, $\mathrm{D}_{95 \%}$ ), the maximum and minimum dose should be related to a specific tissue volume (for example, $\mathrm{D}_{2 \%}$ or preferably $\left.\mathrm{D}_{1 \mathrm{~mm}}\right)^{3}$, and the median dose $\left(\mathrm{D}_{50 \%}\right)$ should be recorded routinely. The Integral Dose becomes the Total Absorbed Energy (TAE). In the assessment of planning quality, the use of the Target Coverage Ratio (TTV/ GTV), Paddick Conformity Index (PCI = TTV $2 /[$ GTV $\times$ PIV $]$ ), New Conformity Index $\left(\mathrm{NCI}=[\mathrm{GTV} \times \mathrm{PIV}] / \mathrm{TTV}^{2}\right)$, Selectivity Index $($ TTV/ PIV), Homogeneity Index $\left(\mathrm{HI}=\left[\mathrm{D}_{2 \%}-\mathrm{D}_{98 \%}\right] / \mathrm{D}_{50 \%}\right)$, and Gradient Index $\left(\mathrm{GI}=\mathrm{PIV} \mathrm{F}_{0.5} / \mathrm{PIV}\right)$ are reemphasized. In relation to the dose to Organs at Risk (OARs), the emphasis is on dose volume recording of the $\mathrm{V}_{\mathrm{ATD}}$ or the dose/volume limit (for example, $\mathrm{V}_{10}$ ) in most cases, with the additional use of a Maximum Dose to a small volume (such as $1 \mathrm{~mm}^{3}$ ) and/or a Point Dose and Mean Point Dose in certain circumstances, particularly when referring to serial organs. The recommendations were accepted by the International Leksell Gamma Knife Society by a vote of $92 \%$ to $8 \%$.

Conclusions. An agreed-upon and uniform terminology and subsequent standardization of certain methods and procedures will advance the clinical science of stereotactic radiosurgery.

(http://thejns.org/doi/abs/10.3171/2014.7.GKS141199)

\section{KEY WORDS • stereotactic radiosurgery • Gamma Knife • standardization • dosimetry}

Abbreviations used in this paper: ATD = Accepted Tolerance Dose; $\mathrm{AVM}=$ arteriovenous malformation; $\mathrm{BED}=$ Biological Equivalent Dose; $\mathrm{CI}=$ Conformity Index; CTV = Clinical Target Volume; $\mathrm{D}_{50 \%}=$ Median Dose; $\mathrm{D}_{\mathrm{V} \%}=$ Absorbed Dose $; \mathrm{GI}=$ Gradient Index; GTV = Gross Target Volume or Gross Tumor Volume; HI = Heterogeneity Index or Homogeneity Index; IAEA = International Atomic Energy Agency; ICRU = International Commission on Radiation Units and Measurements; IM = Internal Margin; ITV = Internal Target Volume; LGKS = Leksell Gamma Knife Society; LINAC $=$ linear accelerator; Maximum Dose $=\mathrm{D}_{\max }$; Mean Dose $=$ $\mathrm{D}_{\text {mean }} ;$ Median Dose $=\mathrm{D}_{\text {median }} ;$ Minimum Dose $=\mathrm{D}_{\min } ; \mathrm{NCI}=\mathrm{New}$ Conformity Index = NCI; OAR = Organ at Risk; PCI = Paddick Conformity Index; PIV = Prescription Isodose Volume; PRV = Planning Organ at Risk Volume; PTC = Percentage Target Covered; PTV = Planning Target Volume; QUANTEC = "Quantitative Analyses of Normal Tissue Effects in the Clinic;" TAE = Total Absorbed Energy; TTV = Treated Target Volume; TV = Target Volume; $\mathrm{V}_{\mathrm{ATD}}=$ Volume of Accepted Tolerance Dose. $\neg$ HE original concept of stereotactic radiosurgery arose within the specialty of neurosurgery, ${ }^{32}$ and the majority of intracranial radiosurgical procedures have been performed using the Leksell Gamma Knife system (Elekta AB, Stockholm, Sweden) - probably more than 800,000 cases as of $2013 .^{31}$ This has involved the empirical elaboration of neurosurgery-based terms and procedures in parallel with radiotherapy. To improve coordination and communication, both across disciplines and between practitioners, there is a need for standardization.

The present report follows an internal proposal in 2010 that radiosurgical terminology and procedures may require modification. A working group of the Leksell Gamma Knife Society (LGKS) drafted a white paper with recommendations for standardization of terminology, which was presented at the 16th international meeting of 
the Society in Sydney in 2012. Following a discussion, a vote was taken from 138 delegates in attendance with a $75 \%$ response rate. The draft document was accepted by $86 \%$ to $14 \%$ subject to suggested revisions. Following circulation of the revised recommendations (printed below) to members of the LGKS, an Internet vote in September 2012 resulted in $92 \%$ acceptance with 211 votes (13.9\% of 1521 emails circulated, although it is likely that a proportion of these emails were obsolete or duplicate).

The objectives of this report are to identify areas of variability and inadequacy and to agree on a terminology that can be applied across therapeutic platforms and disciplines to ensure more uniform reporting. This, in turn, will improve scientific communication and facilitate meaningful comparisons of clinical outcomes in meta-analyses as well as define the minimum reporting requirements for any procedure, paper, or communication. Although the primary intention is to provide recommendations for Gamma Knife users, the suggested terminology is technology independent and could be applied to all radiosurgical treatments, allowing for more general agreement on terminology between clinicians practicing with different technologies.

This report is a first attempt to bring Gamma Knife users in line with international radiotherapy standards by offering suggestions for standardizing the terminology used for reporting treatment parameters. This is based on local agreement within the Gamma Knife Society. It is intended to be a catalyst for further revisions and the development of a final consensus statement, and therefore this particular document as such has no medicolegal implications.

This also is an appropriate moment for such an initiative because the International Commission on Radiation Units and Measurements (ICRU) is proposing a new report provisionally entitled "Prescribing, Recording, and Reporting Stereotactic Treatments with Small Photon Beams." Our report helps identify particular practical requirements of radiosurgery that, inevitably, differ from those of traditional radiotherapy and thereby may complement the ICRU report.

The following report is constructed with two components in each section, first, a review of current terminology and comments on any inconsistencies (Sections 4.1; 5.1; and 6.1) and second, a series of recommendations for improvement (Sections 3.1; 4.2; 5.2; and 6.2). It is emphasized that the contents of the first component, especially comments on the definition of radiosurgery, are not presented as recommendations.

\section{Introduction}

The report presents definitions of the terminology associated with cranial radiosurgery treatment. This does not exclude future extension of standardization to the spine or other areas. The definitions are technology independent.

All definitions are intended to be compatible with ICRU reports, especially Report $62^{22}$ (1999) and Report $83^{62}$ (2010), except where innovations are required by the specific demands of radiosurgery. As far as possible, the definitions are descriptive without implying underlying assumptions that may later prove to be incorrect or incomplete.

It is hoped that this consensus will inspire discussions leading to more general agreement on terminology between technologies within the radiosurgical community. Meanwhile, those members submitting papers to the International Leksell Gamma Knife Society will be expected to conform to these standards.

This report covers the following areas:

- Target delineation and volume measurement

- Dose prescription and measurement (target)

- Dose definition in areas of risk

The committee wishes to acknowledge the input, comments, and advice of the many people who have helped in the elaboration of this report, including several non-Gamma Knife users.

\section{Objectives of This Standardization Report}

- To identify areas of controversy, confusion, and imprecision in terminology and to clarify disputed issues to ensure more uniform reporting

- To make suggestions that may improve the standard of scientific communications and allow easier comparison of work in meta-analysis

- To define the minimum reporting requirements for any procedure, paper, or communication

\section{Definition of Stereotactic Radiosurgery}

"Stereotactic radiosurgery" uses externally generated ionizing radiation to inactivate or eradicate a defined target with the aim of such conformity between the target volume and the prescription dose that is delivered that there is no significant radiation dose outside the target.

A number of definitions of stereotactic radiosurgery have been sanctioned by societies and disciplines, $, 1,3,30,35$ but in reality there is currently no agreed-upon definition nor is such a definition relevant to the present report. The discipline is evolving and should be unconstrained by an official definition. However, for the purposes of this report, stereotactic radiosurgery practice includes the following:

- A target for which the margin and position in space can be delineated radiologically, verified, and either immobilized or any movement compensated mechanically in real time with an accuracy of within $1 \mathrm{~mm}$

- A system for stereotactic guidance of radiation output with submillimeter accuracy

- The ability to plan treatment with sufficient accuracy, conformity, and selectivity to avoid significant normal tissue complications, despite the use of high radiation doses

"Fractionated radiosurgery" implies that the repeated treatment is directed to the same target and with the same dose distribution. In semantic terms, it has not been distinguished from stereotactic radiotherapy except by an arbitrary limit of 5 sessions. However, stereotactic radiotherapy does not, in general, use a dose distribution with a steep falloff as does radiosurgery. 
"Staged radiosurgery" may imply that repeated sessions focus on different areas of one target, a different target at a different time, or the same target with a large time interval. Staging has also been equated with hypofractionation.

\subsection{Recommendation}

Any description of radiosurgery should include the number and type of sessions and the time interval between them and, if multiple, state whether the same or different treatment volume or location is treated with each session.

\section{Target Delineation and Volume Measurement}

The process of radiological delineation or contouring is the largest source of potential error or interobserver variation particularly related to variable or asymmetrical tissue enhancement on T1 MR imaging. For example, a positional shift of $2.8 \pm 2.6 \mathrm{~mm}$ in contouring of arteriovenous malformations (AVMs) has been described. ${ }^{8} \mathrm{~A}$ contouring consensus, both for the target and organs at risk (OARs), should be the subject for a separate standardization report. Any contouring or delineation recommendations in the current report should be considered provisional until such a consensus statement is prepared.

\subsection{Terminology and Definitions Currently In Use}

The terminology in current use for defining volume in the various disciplines and comments on its applicability follow.

\subsubsection{ICRU Reports}

\section{Gross Tumor Volume.}

The Gross Tumor Volume (GTV) is the gross demonstrable extent and location of the malignant growth ${ }^{22}$ or tumor. ${ }^{62}$

Evidently the term "malignant" is not appropriate here for radiosurgery nor are the terms "tumor" or "growth" correct in all cases. The equivalent in radiosurgery would be Gross Target Volume (GTV) or simply Target Volume (TV).

\section{Clinical Target Volume.}

The Clinical Target Volume (CTV) is a tissue volume that contains a demonstrable GTV and/or subclinical malignant disease that must be eliminated. This volume must be treated adequately to achieve the aim of radical therapy. ${ }^{22}$

This term could be applied in radiosurgery for some diagnoses because the concept of CTV is relevant in malignant disease (for example, the margin around a metastasis).

\section{Internal Margin and Internal Target Volume.}

The Internal Margin (IM), commonly asymmetric around the CTV, is intended to compensate for all movements and all variations in site, size and shape of the organs and tissues contained in or adjacent to the CTV. ${ }^{22}$

The Internal Target Volume (ITV) is not relevant in frame-based cranial radiosurgery if no target movement is anticipated.

\footnotetext{
Planning Target Volume.

The Planning Target Volume (PTV) is a geometrical con-
}

cept used for treatment planning, and it is defined to ensure that the prescribed dose is actually delivered to the CTV/ITV in the presence of geometrical uncertainties. ${ }^{22}$

Treated Volume. The Treated Volume (TV) is the total tissue volume that receives the chosen treatment dose.

The Treated Volume is the tissue volume that (according to the approved treatment plan) is planned to receive at least a dose selected and specified by the radiation oncology team as being appropriate to achieve the purpose of the treatment, e.g., tumor eradication or palliation, within the bounds of acceptable complications. ${ }^{22}$

This is equivalent to the Prescription Isodose Volume (PIV) in radiosurgery treatments.

\section{Irradiated Volume.}

The Irradiated Volume is the tissue volume that receives a dose that is considered significant in relation to the tolerance of normal tissue. ${ }^{22}$

The Irradiated Volume has no official abbreviation. In the case of cerebral radiosurgery, this term is exemplified, for instance, by the 8-, 10-, or 12-Gy volume.

\section{Organ at Risk and Planning Organ at Risk Volume.}

Organs at Risk ("critical normal structures") are normal tissues (e.g., spinal cord) whose radiation sensitivity may significantly influence treatment planning and/or prescribed dose. ${ }^{22}$

The Planning Organ at Risk Volume (PRV) is not specifically defined but includes the margin that must be added to the Organ at Risk (OAR or OR) to compensate for any movement during treatment as well as the uncertainties in the setup during the entire treatment course.

\subsubsection{Gamma Knife Radiosurgery}

Target Volume (TV), Also Called Gross Target Volume $(G T V)$. There is possible confusion with the ICRU term Treated Volume, which is abbreviated as TV and also with the term Target/Tumor. The concept of a Planning Target Volume (PTV) has not been employed in frame-based treatment because of the perceived absence of geometrical uncertainties in the system. The Internal Volume Target (ITV) is also not employed, because no internal target movement is anticipated. These comments may need to be revised in relation to the use of relocatable frames if repositioning errors are significant.

Prescription Isodose Volume. The Prescription Isodose Volume (PIV) is the volume that receives the prescription dose (see below); it is also called the planning, planned, or peripheral volume. This is equivalent to the ICRU term Treated Volume.

Treated Target Volume. Treated Target Volume is the volume within the target volume that receives the prescription dose. It has not been dignified with an agreedupon name until now but has a variety of abbreviations including $\mathrm{TV}_{\mathrm{PIV}}$ (in centers using TV), GTV in PIV (in centers using GTV), and $\mathrm{V}_{\mathrm{T}} \cap \mathrm{V}_{\mathrm{P}}$ or PIVTV.

Organ at Risk Volume. This term is equivalent to the ICRU definition. It does not explicitly include accommodation to geometrical positioning uncertainties. 


\subsubsection{LINAC Radiosurgery}

Linear accelerator (LINAC) radiosurgery planning in general uses ICRU terminology. The term Prescription Isodose Volume (PIV) has widespread acceptance.

\subsection{Recommendations for Recording and Reporting Volumes}

\section{Imaging Techniques}

The imaging techniques (including the dose of contrast material) and the contouring method used for target delineation should be stated in any communication. Effort should be made to include the details of acquisition (for example, the type of scanner, field strength, MR sequence, and slice thickness).

\section{Reporting Volumes}

All volume assessments, both at treatment and followup, should be evaluated by direct volume measurement and not by a calculation from diameters. The method of volume calculation should be stated. The measurement of volume change after treatment may also be expressed as a percentage change in volume from the pretreated value. The recommendations of this report for volume assessment are summarized in Table 1.

\section{Target Volume/Gross Target Volume}

The term Target Volume (TV) is used by $54 \%$ of Gamma Knife centers. This term is inconsistent with the ICRU term Gross Target Volume (GTV). Because of widespread use of $\mathrm{TV}$, both terms are considered acceptable in the short term, but the aim is to adopt the ICRU term to improve consistency across all publications, radiosurgical technologies, and disciplines. In cerebral malignant disease the target volume could be equivalent to the Clinical Target Volume (CTV) if a margin is added for presumed, but radiologically undemonstrated, local infiltration. In frame-based cranial radiosurgery, the ICRU term Planning Target Volume (PTV) is considered by the community to be equivalent to TV. If evidence demonstrates geometrical uncertainty in targeting, the adoption of PTV would be appropriate. Internal Margin (IM) and Internal Target Volume (ITV) are not currently considered relevant to frame-based radiosurgery practice.

\section{Prescription Isodose Volume}

The term Prescription Isodose Volume (PIV) is recommended in preference to the terms Planning, Planned, or Peripheral Isodose Volume.

\section{Treated Target Volume}

Because of the many abbreviations for this parameter, the new, simpler, and perhaps more intuitive term Treated Target Volume (TTV) is recommended. The abbreviation TTV should replace $\mathrm{TV}_{\mathrm{PIV}}$, GTV in PIV, $\mathrm{V}_{\mathrm{T}} \cap \mathrm{V}_{\mathrm{P}}$, and PIVTV. The TTV refers to the volume within the target that meets or exceeds the prescription dose.

\section{Organ at Risk Volume}

All anatomical structures should be delineated in the reconstructed imaging planes that are least likely to cause volume artifacts. Also, delineations should be performed
TABLE 1: Summary of recommended terminology relating to volume measurement

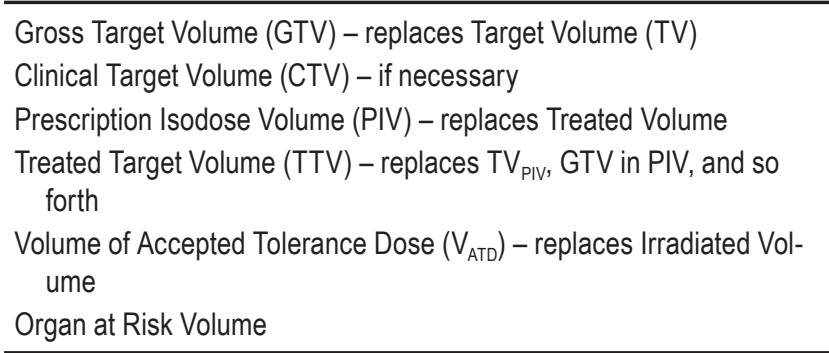

using the most anatomically appropriate and geometrically correct MRI sequences.

\section{Dose Prescription and Measurement (Target)}

\subsection{Terminology and Definitions Currently In Use}

The terminology in current use for defining radiation dose in the various disciplines and comments on its applicability follow.

\subsubsection{ICRU Reports}

The ICRU term "reference dose" is no longer recommended. Instead use the Absorbed Dose $\left(\mathrm{D}_{\mathrm{v} \%}\right)$ where $\mathrm{V} \%$ is the percentage of the volume covered by the specified dose. The maximum and minimum doses should be replaced by dose-volume reporting (for example, $\mathrm{D}_{2 \%}$ or $\mathrm{D}_{98 \%}$, respectively). It is recommended that the dose for the OAR should include the "maximum" dose $\mathrm{D}_{2 \%}$ to the PRV (serial-like organs) or the mean or median dose (parallel-like organs) (a 2007 report from the International Atomic Energy Agency [IAEA $]^{19}$ and a 2010 report from the ICRU ${ }^{62}$ ). Documents vary as to whether the absorbed dose should be accompanied by a percentage sign $\left(\mathrm{D}_{2 \%}\right)$ or without one $\left(\mathrm{D}_{2}\right)$.

\subsubsection{Gamma Knife Radiosurgery}

The Prescription Dose (sometimes called Peripheral Dose or Marginal Dose) is the minimum dose intended to cover most, if not all, of the target volume. The Prescription Dose may not always cover the entire target, for instance, when one is suboptimally treating a pituitary tumor in contact with the optic chiasm.

The Prescription Isodose (\% isodose) is the percentage of the maximum dose that is chosen to conform to the periphery of the target. The use of the term Prescription Isodose Volume (PIV) (see earlier discussion) implies acceptance of the term "prescription isodose and prescription dose."

Maximum Dose $\left(D_{\max }\right)$. Maximum point-based dose reporting can be misleading due to the nature of the calculation and dose grid. There are two recognized alternatives applied to reporting a more representative value. See the following examples:

1. The maximum dose over a $1-\mathrm{mm}^{3}$ region.

2. The absorbed dose (for example, $\mathrm{D}_{2 \%}$ ), which conforms to the recommendations of the IAEA and the ICRU. 
As a percentage, this value is dependent on the total volume of the target or structure.

Minimum Dose $\left(D_{\min }\right)$. Minimum point-based dose reporting can be misleading due to the nature of the calculation and dose grid. There are two recognized alternatives applied to reporting a more representative value. See the following examples:

1. The minimum dose over a $1-\mathrm{mm}^{3}$ region.

2. The absorbed dose (for example, $D_{98 \%}$ ), which conforms to the recommendations of IAEA and ICRU. As a percentage, this value is dependent on the total volume of the target or structure.

Mean Dose. The Mean Dose $\left(\mathrm{D}_{\text {mean }}\right)$ is the total energy absorbed by the target divided by the mass of the target. The planning system usually calculates the value of the mean dose.

Median Dose. Median Dose $\left(\mathrm{D}_{\text {median }}\right)$ is a new term that describes the absorbed dose that covers $50 \%$ of the target (ICRU Report 8362) and is referred to as the median absorbed dose, $\mathrm{D}_{50 \%}$, or $\mathrm{D}_{\text {median }}$.

Integral Dose. The Integral Dose is actually the sum of absorbed energy over the target volume in units of milliJoules $(\mathrm{mJ})$, in effect the multiplicative product of dose $(\mathrm{J} / \mathrm{kg})$ and mass $(\mathrm{kg})$. This historical term is somewhat confusing due to the incorrect reference to "dose." It is suggested that the term Total Absorbed Energy (TAE), which is the amount of energy imparted to the target, should be used in preference.

Dose Rate. This is a complex quantity that is difficult to quote as a single number. A detailed description of the treatment parameters would provide sufficient information to reconstruct effective dose rates. Therefore, it is necessary to quote the source output (current dose rate/treatment dose rate); the number, size and location of isocenters; beam-on time (minutes); and total treatment delivery time (minutes) including breaks.

\subsubsection{LINAC Radiosurgery}

Linear accelerator (LINAC) radiosurgery planning in general uses ICRU terminology. The terms Prescription Dose and Prescription Isodose have widespread acceptance.

\subsubsection{Assessment of Plan Quality}

Coverage Index. An original definition (1994) for radiosurgery quality assurance guidelines reads as follows:

The coverage index is the target iso-dose as a fraction of the prescription isodose. If the iso-dose line corresponding to $90 \%$ of the prescribed dose completely encloses the target, the plan is considered to follow protocol. If less than $90 \%$ but more than $80 \%$ of the prescribed dose completely encloses the target, the plan is considered a minor deviation. In all other variations, it is a major deviation..$^{30}$

The limits prescribed in this definition are not appropriate for radiosurgery.

Target Coverage Ratio is defined in this report as the proportion of the target volume that is encompassed by the Prescription Isodose Volume. The index has also been presented as percent coverage-Percentage Target Covered (PTC). ${ }^{7}$

Alternatively, use of the term $\mathrm{D}_{95 \%}(95 \%$ coverage dose), as derived from the dose-volume histogram, would give users the ability to compare doses given across different series in an objective way and conforms to the directives of the ICRU.

Conformity Index. The Conformity Index (CI) also defines how adequately a target is covered by treatment.

A Conformity Index (CI) can be employed when the PTV is fully enclosed by the Treated Volume, then being the quotient of the Treated Volume and the volume of the PTV. ${ }^{22}$

This definition has been considered less than satisfactory because the Treated Volume and PTV are not necessarily concentric and symmetrical.

This inadequacy has led to the development of the Paddick Conformity Index (PCI). ${ }^{48}$ This value is the coverage multiplied by the Selectivity Index:

$\mathrm{TV}_{\mathrm{PIV}^{2}} /(\mathrm{TV} \times \mathrm{PIV})$.

A perfect plan has a score of 1 , whereas less perfect plans have a score of $<1$. An ideal value for PCI conformity could be $>0.85$.

The Paddick Conformity Index is also known as the New Conformity Index (NCI), in which case the formula is inverted and less-than-perfect plans score more than 1 .

$(\mathrm{TV} \times \mathrm{PIV}) / \mathrm{TV}_{\mathrm{PIV}^{2}}$

An ideal value for the NCI conformity could be $<1.18$.

Selectivity Index. If a compound conformity index (PCI or NCI) is not used, a measure of selectivity may be required. Selectivity is defined by how much normal tissue around the target is spared. The ratio is the volume of the target covered by the peripheral isodose divided by the total peripheral isodose volume.

$\mathrm{TV}_{\mathrm{PIV}} / \mathrm{PIV}$

An ideal value for selectivity could be $>0.9$.

Homogeneity Index. The Homogeneity Index, or HI (also called the Heterogeneity index), is the ratio of the maximum dose to the prescription isodose. The new definition of homogeneity (ICRU Report $83^{62}$ ) is as follows:

$\mathrm{HI}=\left(\mathrm{D}_{2 \%}-\mathrm{D}_{98 \%}\right) / \mathrm{D}_{50 \%}$

Studies are required to determine whether a high Homogeneity/Heterogeneity Index has any association with increased morbidity.

Gradient Index. The Gradient Index (GI) is the ratio of the volume enclosed by half of the prescription isodose, which is divided by the Prescription Isodose Volume. ${ }^{49}$

$\mathrm{PIV}_{0.5} / \mathrm{PIV}$

This is sometimes known as the 25/50 ratio, which assumes a constant prescription isodose of $50 \%$, which is incorrect. An ideal value for the Gradient Index could be $<3.0$. 


\subsection{Recommendations for Recording and Reporting Dose and Planning Quality}

\section{Dose Computation}

The algorithm used to express the dose delivered (for example, TMR 10, TMR Classic or Convolution in GammaPlan) must be quoted since the dose may vary depending on the algorithm used.

\section{Prescription Dose}

This report recommends the use of the term Prescription in relation to Dose and Isodose, rather than Planning, Planned and Peripheral or Marginal. The recommendations of this report for dose prescription and measurement are summarized in Table 2.

\section{Absorbed Dose}

The Absorbed Dose calculated over a standard volume of the target is recommended by the ICRU and would be an improvement for radiosurgery. The use of the Prescription Dose when recording treatment does not reveal how much of the target was covered by that dose. Adding the percent coverage does not allow a comparison between cases and series. It is recommended that a standard absorbed dose value such as $\mathrm{D}_{95 \%}$ should be recorded for all treatments.

\section{Biological Dose}

It should be noted that the use of Dose/Volume recording may need to be replaced by Biological Equivalent Dose (BED)/Volume recording for improved accuracy at some time in the future.

\section{Maximum and Minimum Dose}

It is necessary to make a decision on the preferred recording parameter for Maximum and Minimum Dose. This may be deferred until after the contouring consensus report. Meanwhile 2 methods are acceptable. Maximum Dose and Minimum Dose may be recorded and quoted as the maximum and minimum doses directed to a specified relevant subvolume (for example, $1 \mathrm{~mm}^{3}$ ) of the target or OAR. It may also be recorded as absorbed doses: $\mathrm{D}_{2 \%}$ or $\mathrm{D}_{98 \%}$ respectively.

\section{Coverage}

In a publication the author's definition of coverage should be explicitly specified in all published clinical series. As noted above, this report recommends additional notation of the standard dose to $95 \%$ of the target $\left(D_{95 \%}\right)$.

\section{Planning Quality}

The present abbreviations representing the target coverage ratio are somewhat confusing. It is recommended that, with the use of Treated Target Volume (TTV) and the more universal adoption of GTV, the target coverage ratio should become TTV/GTV.

Other metrics include the following:

$$
\begin{aligned}
& \text { PIV) } \\
& \text { TTV }^{2} \text { New Conformity Index }(\mathrm{NCI})=(\mathrm{GTV} \times \mathrm{PIV}) / \\
& \text { Selectivity Index }=\mathrm{TTV} / \mathrm{PIV}
\end{aligned}
$$$$
\text { Paddick Conformity Index }(\mathrm{PCI})=\mathrm{TTV}^{2} /(\mathrm{GTV} \times
$$

\section{TABLE 2: Summary of recommended terminology relating to dose prescription and measurement}

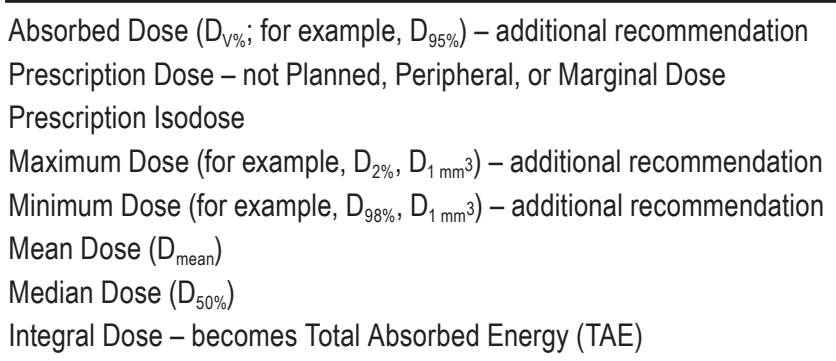

It should be noted that the significance of radiosurgical planning quality indexes is related to target volume, for which the results for very small and larger targets may not be comparable. A full evaluation of radiosurgical planning quality requires the assessment of several factors-usually Coverage, Selectivity, and Gradient Index. The PCI/NCI combines the first 2 factors into 1 figure. It may be demonstrated that a Homogeneity Index (HI) is also necessary. It is recommended that all 4 of these quality assurance indexes be recorded (or 3 if coverage and selectivity are combined as PCI/NCI). Further prospective studies are needed to determine the relevance of planning quality assessment to clinical outcome. The recommendations of this report concerning planning quality are summarized in Table 3.

\section{Dose Definition in Areas of Risk}

\subsection{Terminology and Definitions Currently In Use}

The terminology in current use for defining dose in the various disciplines and comments on its applicability follow. It must be emphasized that, in reports quoting numerical values for normal tissue dose tolerances, these are only guidelines drawn from limited experience. An important reason for standardizing terminology is to allow the collection of high-quality dose and effects data to build more accurate models of the risk to normal tissues and guide the creation of treatment plans that maximize the therapeutic ratio.

\subsubsection{ICRU Reports}

\section{Maximum Dose to Organ at Risk (OAR).}

Absorbed Dose $\left(D_{V \%)}\right.$. The dose for the OAR should include the "maximum" dose $\mathrm{D}_{2 \%}$ (serial-like organs) and the mean or median dose (parallel-like organs). Because most organs are not clearly serial-like or parallel-like structures, at least 3 dose-volume specifications should be reported. These would include the $\mathrm{D}_{\text {mean }}, \mathrm{D}_{2 \%}$, and a third specification, $\mathrm{V}_{\mathrm{D}}$, which correlates well with an Absorbed Dose $\left(\mathrm{V}_{\mathrm{D} \%}\right)$, which if exceeded within some volume has a known high probability of causing a serious complication (IAEA report from 2007,19 ICRU report from 201062).

6.1.2 "Quantitative Analysis of Normal Tissue Effects in the Clinic"

The normal tissue dose tolerance for the brain, optic 
TABLE 3: Summary of recommended terminology relating to planning quality

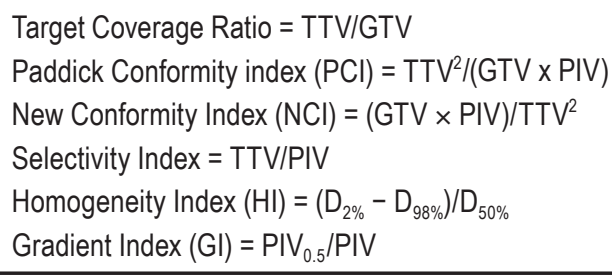

nerves and chiasm, brainstem, and spinal cord has been reviewed in a journal supplement entitled "Quantitative Analyses of Normal Tissue Effects in the Clinic" (QUANTEC). ${ }^{41}$ It was recognized that although QUANTEC provided recommendations for radiosurgery, the data supporting these recommendations were limited and further efforts to collect applicable data by the radiosurgery community would improve these recommendations.

Brain (Hemisphere). The incidence of radionecrosis depends on the dose, volume, region irradiated, and pathology. The substantial variation in reports from various treatments and centers has prevented precise risk predictions except in specific pathologies (for example, AVMs).

The term Maximum Tolerated Dose was used in Radiation Therapy Oncology Group Protocol 90-05.56

Primary toxicity predictors were treated volume and volumes at 10 and $12 \mathrm{~Gy}\left(\mathrm{~V}_{10}, \mathrm{~V}_{12}\right)$. The relationship between volume irradiated at 10 or $12 \mathrm{~Gy}$ and the percent incidence of radionecrosis is not linear.

The recommendation of QUANTEC is to report $\mathrm{V}_{12}$ and the location of treatment.

Optic Pathway. Primary toxicity predictors that have been reported include the Prescription Dose and the maximum dose to the optic pathway $\left(\mathrm{D}_{\max }\right)$ with recommended limits between $<8$ Gy and $<12$ Gy.

The recommendation of QUANTEC is for multiinstitutional studies using dose-volume histogram analysis, consistency in contouring the optic pathway, agreement on measurement of vision, and reporting of relevant concurrent drug treatment.

Brainstem. With respect to the Prescription Dose, $\mathrm{D}_{\max }$, to the target, more adequate information is required.

The recommendation of QUANTEC is to report brainstem $\mathrm{D}_{\text {max }}, \mathrm{D}_{\text {mean }}$, and $\mathrm{D}_{\text {lcc }}$ and to encourage dosevolume reporting.

Spinal Cord. $\mathrm{D}_{\max }, \mathrm{D}_{0.1 \mathrm{lc}}, \mathrm{D}_{1 \mathrm{cc}}, \mathrm{D}_{1}, \mathrm{D}_{10}, \mathrm{D}_{25}$ are all used and their values in radiosurgery are reported but not adequately discussed in the QUANTEC document.

The recommendation of QUANTEC is to record the position of the lesion, the cord volume, the number of segments involved, the number of fractions, $\mathrm{D}_{\max }, \mathrm{D}_{1}, \mathrm{D}_{10}, \mathrm{D}_{50}$, $\mathrm{D}_{0.1 \mathrm{cc}}, \mathrm{D}_{1 \mathrm{cc}}$, and concurrent therapies.

\subsubsection{Gamma Knife Radiosurgery}

The maximum dose to a critical structure may be inaccurate due to vagaries of computation that can overestimate the clinically relevant maximum dose, which has also been expressed as the maximum dose to a specific small volume (for example $1 \mathrm{~mm}^{3}$ ) or to the $\mathrm{D}_{\mathrm{v} \%}$ (for example $\left.\mathrm{D}_{2 \%}\right)$.

The mean dose to a critical structure is highly dependent on the total volume that is outlined and is of little use except in small, constant areas such as the cochlea. The concept of mean point dose in a structure such as the hypothalamus or pituitary stalk has been promoted. ${ }^{14}$

The dose/volume limit (for example $\mathrm{V}_{8}, \mathrm{~V}_{10}, \mathrm{~V}_{12}$ ) is becoming more regularly used.

\subsubsection{LINAC Radiosurgery}

Many units follow the recommendations of American Association of Physicists in Medicine Task Group 101, which are primarily related to stereotactic body radiotherapy but provide a table of suggested dose constraints including for "one fraction" treatment. ${ }^{6}$

\subsection{Recommendations for Recording and Reporting Doses in Areas of Risk}

\subsubsection{General Recommendations}

The nature of adjacent organs reflects risks to these organs, which may depend on the volume irradiated, the length of a structure involved, or a maximum point dose. It has been suggested that the dose for an OAR should be represented by the "maximum" dose $\mathrm{D}_{2 \%}$ to the Planning Organ at Risk Volume (PRV) in serial-like organs or the mean or median dose in parallel-like organs (a 2007 IAEA report ${ }^{19}$ and a 2010 ICRU report ${ }^{62}$ ). The latter definition, in particular, is considered by this report to be inadequate. The recommendations of this report concerning doses to OARs are summarized in Table 4.

When the recording of maximum dose to a critical structure is considered appropriate, it is recommended that it be expressed either as the maximum dose to a volume $\mathrm{V}$ in cubic millimeters or as the dose to a percent of the total volume of the organ $\left(\mathrm{D}_{\mathrm{V} \%}\right)$ until it has been demonstrated which measure is more meaningful in terms of clinical impact. The size of the appropriate $\mathrm{V}$ in relation to each OAR requires definition. A contouring consensus for normal tissues should be the subject of a separate standardization report. Any contouring or delineation recommendations in the current report should be considered provisional until such a consensus has been prepared.

The use of the term Accepted Tolerance Dose (ATD) is suggested and should be used whenever possible. The recommended dose limit should be related to a specific volume of the area at risk (for example, "12-Gy volume should be less than $30 \mathrm{~mm}^{3 \text { ") }}$ ) and the actual value recorded with the relevant agreed-upon abbreviation (for example, $\mathrm{V}_{12}$ and not $12 \mathrm{GV}$ ). Specific values for the ATD are not given in this report since there is insufficient experience to draw conclusions that might have medicolegal significance.

When a specific ATD for a particular tissue has been defined, then the volume exposed at that critical level (Volume of Accepted Tolerance Dose $\left[\mathrm{V}_{\text {ATD }}\right]$ ) should always be quoted. Until there is an agreed-upon definition of ATD, it is suggested that volumes exposed at a number of relevant levels (for example 4, 6, 8 Gy, and so forth, depending on the tissue) should be calculated and recorded. 


\section{TABLE 4: Summary of recommended terminology relating to dose to organs at risk*}

Maximum Dose to (for example) $1 \mathrm{~mm}^{3}$ or $100 \mathrm{~mm}^{3}$ - additional rec-
ommendation
Maximum Dose $\mathrm{D}_{2 \%}$ - additional recommendation (provisional)
Point Dose
Mean Point Dose
Mean Dose $\left(\mathrm{D}_{\text {mean }}\right)$
Median Dose $\left(\mathrm{D}_{50 \%}\right)$
Volume of Accepted Tolerance Dose $\left(\mathrm{V}_{\text {ATD }}\right)$ - dose/volume limit (for ex-
$\quad$ ample, $\left.V_{10}\right)$

* Depending on organ at risk (serial, parallel, and so forth).

\subsubsection{Recommended Procedures in Specific Areas}

The Volume of Accepted Tolerance Dose $\left(\mathrm{V}_{\mathrm{ATD}}\right)$ should not include the target volume except in cases in which the target is enclosed in an organ or structure at risk. These cases are discussed in more detail in the paragraphs below.

Brain (Hemisphere). Brain-irradiated volume in relation to tolerance should be expressed and recorded as a measured volume of brain that receives a dose over a certain accepted threshold (for example, $\mathrm{V}_{10}, \mathrm{~V}_{12}$ ). This is not the same as the 10- or 12-Gy volume with target volume excluded, called "Marginal-12-Gy-Volume" by Flickinger et al. ${ }^{15}$ and "volume of nontarget tissue $\left(\mathrm{V}_{\mathrm{NTD}}\right)$ " by Petti et al., ${ }^{50}$ which also may have importance and may be recorded in parallel. An Accepted Tolerance Dose (dose/volume limit) needs to be related also to the site of the lesion and the condition being treated.

Brainstem. The brainstem volume should include adequate slices above and below the target to encompass all of the isodoses being measured. An Accepted Tolerance Dose (dose/volume limit) needs to be established. Record the volumes irradiated with 10 and 12 Gy. If the greater part of the target is within the brainstem the target volume is included in the 10- or 12-Gy volume; if it is outside the brainstem it is not included in the 10- or 12-Gy volume.

Cochlea. The most sensitive areas in the cochlea are the organ of Corti and the stria vascularis. ${ }^{33}$ The basal turn of the cochlea is responsible for hearing in the higher frequencies, which are those most often affected by radiation. Therefore, it is recommended that the whole cochlea from the base of the modiolus and including the whole spiral canal should be delineated. A maximum point dose at the base of the modiolus and the mean dose in the total volume should be recorded. An Accepted Tolerance Dose (dose/volume limit) has not been established as yet, but it is suggested that 4-, 6-, and 8-Gy volumes should be calculated.

Optic Pathway. The optic pathways-nerve(s), chiasm, and optic tracts - should be delineated over the region anticipated to receive at least $4 \mathrm{~Gy}$. It is suggested that the left and right optic nerves, the chiasm, and the left and right optic tracts should be outlined as separate structures. This is to eliminate inadequacies in planning systems such as GammaPlan, which may have difficulty rendering a three-dimensional volume as complex as the optic apparatus. This method will also help distinguish the specific doses received by the different components of the optic tract. Although an Accepted Tolerance Dose (dose/volume limit) needs to be established, it is recommended that 6-, 8-, and 10-Gy volumes should be calculated.

Hypothalamus and Pituitary Stalk. The median eminence of the hypothalamus and pituitary stalk can be delineated as one structure. Although an Accepted Tolerance Dose (dose/volume limit) needs to be established, it is recommended to record the following dose/volume parameters: maximum dose to the structure and the mean point dose ${ }^{14}$ as well as the 4-, 6-, and 8-Gy volumes.

Pituitary Gland. The pituitary gland should be delineated separately from the pituitary stalk. An Accepted Tolerance Dose (dose/volume limit) needs to be established and in the meantime the mean dose to the gland should be recorded ${ }^{40}$ together with the 12- and 15-Gy volumes.

Lens. The maximum or mean point dose is adequate for reporting. At present it is not known whether the maximum or mean point dose is more important for the lens, and it is only by recording these parameters that a predictive value for an accepted tolerance dose will be discovered. Dose-volume histograms of the lens require contouring of this small structure, which is disproportionately burdensome to complete in time compared with the value of the data it may contain. In addition, being a small structure that is distant from the vast majority of Gamma Knife targets, the variation in the dose inside the lens may not vary very much.

Spinal Cord. The spinal cord should be delineated above and below the target far enough to ensure that the volume encompassing relevant isodoses is included. Although an Accepted Tolerance Dose (dose/volume limit) needs to be established, it is suggested that 8-, 10- and 12-Gy volumes should be calculated.

\section{Discussion}

Through empirical advances over the past 25 years, stereotactic radiosurgery has contributed significantly to the overall management of brain lesions. With new technological advances, stereotactic radiosurgery is now delivered both intracranially and extracranially using a number of treatment modalities. It is clear that further progress requires research, clinical trials, and meta-analyses of a higher standard. This will be facilitated by an agreement to use a clear and universal radiosurgical language or nomenclature. Through the development of this report, a number of areas of investigation and improvement have been recognized through a broad interaction with the Gamma Knife community, and it is hoped that this initiative will stimulate such research and facilitate collaboration across disciplines and technologies.

A basic practical principle of radiosurgery is that its accuracy should obviate the need for fractionation, except perhaps in very large targets. In this context it is appropri- 
ate to note that the comments of the ICRU Small Field committee on this subject are that it "deems that [the term] Radiosurgery should be reserved for single fraction treatment. Multiple fractions are referred to as Stereotactic Radiotherapy and could be more than 5 fractions (and generally less than 10)" (J. Seuntjens, personal communication May 11, 2013).

It has been emphasized in the past-and this debate may likely continue - that such a definition runs counter to the American Association of Neurological Surgeons/Congress of Neurological Surgeons definition of radiosurgery that was previously published ${ }^{3}$ as well as to the agreement reached with the American Society for Therapeutic Radiology. It also runs counter to some of the literature and to widely accepted billing practices in the United States. However, this debate and the lack of a universally agreedupon definition of radiosurgery do not alter the principle outlined above and the consequent primacy of measurement accuracy. The condiciones sine quibus non are first, the accurate definition of the target and OAR, and second, the meticulous checking of the accuracy and consistency of dose delivery to the target and avoidance of the OAR.

Reported treatment responses and treatment-related toxicities vary widely in radiosurgery literature. There are multiple biological factors that may have contributed to this variability including individual patient and target radiosensitivity. At the present time, however, there are a number of treatment and reporting factors that may have also amplified this variability including variable target volumes, target delineation, and dose prescription, as well as variable dose limits allowed to organs at risk.

\section{Contouring Consensus}

Despite the general principles of radiosurgery, which recognize the importance of accurately defining target(s) and organs at risk to ensure safe and effective treatment, there has been variability in clinical practice in the delineation of these structures, with some centers contouring all relevant structures and other centers employing minimal or no contouring for radiosurgery planning. A first key step to improving the consistency of target and OAR delineation is to establish a standardized approach for nomenclature and reporting, as described in this report.

Studies have shown that even when efforts are made to consistently define specific volumes, such as target volume, there can be wide interobserver variability. For example, the delineation of an AVM nidus across observers can have positional shifts of $2.8 \pm 2.6 \mathrm{~mm}^{8}{ }^{8}$ Sandstrom ${ }^{54}$ reported wide variability in target delineation with standard deviations ranging from $11 \%$ to $105 \%$ of mean volume across 20 observers, depending on the diagnosis. Similarly, Mitine et $a .^{46}$ described a range of volume variation extending between $35 \%$ and $402 \%$.

In addition to isolated interobserver contouring differences, variability in target delineation has been related also to the radiological method used for contouring. There are known differences between $\mathrm{T} 1$ and $\mathrm{T} 2$ images, with $\mathrm{T} 2$ volumes being $12 \%$ smaller, ${ }^{60}$ and it has also been shown that tumor volume may vary depending on the delay in imaging after administration of contrast material. ${ }^{57}$ The increasing use of image coregistration may add further uncertainty to target localization. Alhough some studies assess the error of coregistration at a submillimeter level, ${ }^{10,26}$ and theoretically subvoxel accuracy is achievable, ${ }^{39}$ others find inconsistencies up to $4 \mathrm{~mm}$ or more. ${ }^{11,58}$ Additionally, variations in volume measurement among different algorithms used in stereotactic surgery planning systems, investigated by Ma et al.. ${ }^{36}$ have been shown to result in volume differences of $3.6 \%-22 \%$ in a phantom and $1.0 \%-10.2 \%$ in a patient. As doses are often modified based on target volume, errors in target delineation and volume measurement can impact the overall treatment plan.

We (the Society) recognize that the variability in delineation of targets and organs at risk that is currently in practice limits our ability to objectively evaluate and optimize radiosurgery treatment to improve its outcomes. Especially with the advanced radiation delivery systems used for radiosurgery, which provide great mechanical precision, the impact of accurate delineation of targets and organs at risk will have significant implications for treatment planning and resulting clinical outcome.

Accordingly, the standardization of terminology and reporting will motivate and facilitate the effort to improve the delineation of target volumes and organs at risk across observers and institutions. Complementary efforts by the Society and the radiosurgical community are in progress to deliver a second report that summarizes a contouring consensus that applies the standardized terms described in this report.

\section{Target Volume and Target Immobilization}

The meaning of the term Target Volume (TV) is selfevident to neurosurgeons involved in radiosurgery but may cause confusion among the radiotherapy community, in which the use of the term in manuscripts has been questioned. Therefore its substitution by the internationally accepted term, GTV, is appropriate now as radiosurgery expands its horizon. In contrast, the term Prescription Isodose Volume (PIV) already has widespread acceptance across disciplines.

The question of the relevance of Internal Target Volume (ITV) and Planning Target Volume (PTV) to radiosurgery is less easy to resolve and depends on the extent of geometrical uncertainties and the accuracy of immobilization of the target. There is an inherent uncertainty in the position of the stereotactic frame related to the focus position of the Gamma Knife, which is usually assessed by film or diode quality assurance, and the variability of this measurement has been shown to be less than 0.2 mm. ${ }^{21}$ The results of evaluating 170 system tests over 5 years showed that the mean displacement vector of the complete Gamma Knife system (including MR imaging) was $0.48 \mathrm{~mm} \pm 0.23 \mathrm{~mm} .{ }^{38} \mathrm{~A}$ similar result for LINACbased stereotactic radiation therapy was $1.1 \pm 0.3 \mathrm{~mm} .{ }^{9} \mathrm{In}$ addition, there may be intrinsic uncertainties in the various evaluation methods of up to $0.3 \mathrm{~mm} .^{51}$ The American Association of Physicists in Medicine Task Group Report 142 has defined $1 \mathrm{~mm}$ as the acceptable upper limit for uncertainty in radiosurgery. ${ }^{27}$

The immobility of the stereotactic frame with relation to the skull has been questioned by Maciunas et al., ${ }^{37}$ 
who suggested there was a potentially significant error in the mechanical accuracy associated with weight bearing; however, a recent more detailed assessment by Karlsson et al. ${ }^{24}$ discounted this, at least for the Leksell frame, because of methodological errors in the Maciunas paper. A preliminary study by Arn and Carlsson ${ }^{2}$ specifically related to weight bearing showed that a $50 \mathrm{~N}(5 \mathrm{~kg})$ load produced only a $0.02-\mathrm{mm}$ deformation in an adult-sized head phantom, although they emphasized that care should be taken with insulated Leksell posts, with which the deformity was slightly greater, and in the small heads of children, in which longer screws allowed a deformity of up to $0.44 \mathrm{~mm}$.

In addition, accuracy depends on the imaging technique that is used and any coregistration error. Sajeev et al. ${ }^{53}$ have evaluated the geometrical accuracies of CT, MR, and image fusion and found that the mean errors in calculating vector distances from the center of the Leksell coordinate system $(100,100,100)$ to a known target volume were $0.22 \mathrm{~mm}, 0.8 \mathrm{~mm}$, and $0.43 \mathrm{~mm}$ for CT, MR, and CT-MR fused images, respectively. Two studies, ${ }^{4,43}$ both of which used image coregistration, evaluated the difference between the frame coordinates and the position of a resulting stereotactically directed lesion, a procedure that evaluates the end-to-end error of the treatment process. Both studies reported a root mean square error of $0.9 \mathrm{~mm}$. This indicates that any coregistration error should be significantly less than $0.9 \mathrm{~mm}$.

With regard to the uncertainty of target position when frame fixation is used, there can be minor target movement, for example with respiration, but this is usually disregarded. Recently, Kartaria et al. ${ }^{25}$ evaluated Leksell frame fixation with cone-beam CT measurements of target position during fractionated treatments; their report shows a root mean square interfraction shift of $0.16 \mathrm{~mm}$. This level of accuracy can only apply to tissues immobile in relation to the skull. Tonetti et al. ${ }^{59}$ have shown movement of up to $4 \mathrm{~mm}$ of targets at the C-1 level with a change of neck position, despite fixation of the skull by the frame.

While the principle of skeletally fixed, frame-based stereotactic radiosurgery is to ensure that geometrical uncertainties are negligible and assumes that target movement requires no compensation by ITV, neither of these assumptions applies to non-frame-based radiosurgery. Using the Elekta EXTEND system, a relocatable frame based on a dental impression and bite block, the mean three-dimensional intrafraction motion was found to be $0.4-0.5 \pm 0.3 \mathrm{~mm} .^{52,55}$

This compares with setup errors for typical frameless immobilization of the head for which Masi et al..$^{42}$ report that results for bite block and mask $(2.9 \pm 1.3 \mathrm{~mm})$ were smaller than those for thermoplastic mask alone $(3.2 \pm 1.5$ $\mathrm{mm}$ ), although statistical significance was not reached ( $\mathrm{p}$ $=0.15$ ). In another study the typical radial overall uncertainty for positioning and fixation for stereotactic radiosurgery using a mask has been recorded as $1.80 \pm 0.60$ $\mathrm{mm} .{ }^{23}$ Do et al. ${ }^{13}$ describe adding an extra margin of $2 \mathrm{~mm}$ when using mask fixation rather than a stereotactic frame.

In summary, it seems that skeletally fixed, framebased radiosurgery has an overall uncertainty of less than $1 \mathrm{~mm}$, which is the level widely regarded as acceptable and for which no accommodation by ITV/PTV is necessary. However, it is clear that, as indications and techniques evolve beyond adequately fixed cranial targets, certain procedural modifications will be necessary. At one extreme, a potential definition of radiosurgery would be a technique that is demonstrably accurate enough to avoid the need for ITV or PTV, or alternatively one in which PTV can be defined as the target volume without margins.

\section{Dosimetry and Assessment of Planning Quality}

The term Prescription Dose does not define the actual dose received by the target. The improvements suggested in this report are the use of Absorbed Dose (for example, $\mathrm{D}_{95 \%}$ ) recommended by the ICRU and the concept of Total Absorbed Energy. However, the effect of radiation may depend in addition on other factors such as the treatment time and the number and size of isocenters.

The evaluation of planning quality in terms of dose conformity and heterogeneity has, in parallel, become very precise, and its evaluation has revealed significant discrepancies. In an examination of the accuracy of dose delivery between 4 platforms, Gevaert et al. ${ }^{18}$ showed variability in the Paddick Conformity Index (PCI) from 0.66 to 0.77 , in the Gradient Index (GI) from 2.59 to 3.94, and in the Heterogeneity Index (HI) from 0.18 to 0.84 .

Are conformity and other indexes of planning quality of fundamental importance in radiosurgery? If not, there is limited purpose to this document. It would seem counterintuitive to suggest that they are not, but a first draft of this standardization initiative was strongly criticized because it did not justify the recording of these parameters on the basis of their proven relevance. It is known that some radiosurgical centers do not always contour the target or OAR and thus cannot derive dose-volume histograms or measure the quality of a plan. Until a representative amount of data that is consistently recorded with a uniform terminology becomes available to support the need for quality control, this practice will continue.

The correlation between planning quality indexes and clinical outcomes has been variable for both the target response and treatment-related toxicity to surrounding tissues. $5,17,20,29,34,44,47$ There have been studies ${ }^{12,61}$ reporting a worse outcome in lesions treated with very conformal plans, although it is possible that this reflects limitations in target delineation and that less conformal plans were more likely to cover microscopic disease. It is also possible that anomalous outcomes may be due to the fact that conformity improves with the increasing size of the lesion, whereas control is associated with smaller target volumes and complications with larger target volumes. This mediates against a simple relationship between conformity and outcome but does not dictate that planning quality indexes should be disregarded.

With treatment-related toxicity, it is well known that the 12-Gy volume in the brain correlates well with the risk of radionecrosis both in tumors and AVMs, ${ }^{16,28}$ but this is more dependent on target volume and dose than on conformity. Freidman et al., ${ }^{17}$ however, found a statistically significant association in AVMs between improved conformality and a lower incidence of transient complications. Also higher dose gradients were correlated with 
radiological success in obliteration. Liscák et al. ${ }^{34}$ used a ratio as an index of conformity (PIV - 20\%/PIV) and found that it was a predictor for facial nerve complications, dizziness, and vertigo after radiosurgery for vestibular schwannoma. Petti et al. ${ }^{50}$ suggest that the range of Conformity Indexes represented in most studies may not be wide enough to show a statistical correlation between improved conformity and decreased toxicity.

The accuracy of radiation delivery is designed to protect adjacent normal tissues but the accepted tolerance dose of these tissues for radiosurgery is in need of a better definition. In current practice dose limits for normal tissue in radiosurgery have evolved empirically and the reported incidence of normal tissue damage is low; however, this may not reflect the true incidence of toxicity because of possible reporting bias and small patient cohorts. The QUANTEC initiative ${ }^{41}$ noted above (Section 6.1.2) reviews the present status of dose limitation to normal tissue but lacks uniformity and depends too much on $\mathrm{D}_{\text {max }}, \mathrm{D}_{\text {mean }}$, and $\mathrm{D}_{\%}$. As outlined in our report, improved consistency in the measurement and reporting of dose to OARs would help determine the dose limits of these tissues for radiosurgery.

This report suggests that the maximum dose directed to a small volume of the organ or structure and the volume of tissue receiving the accepted tolerance dose are appropriate measures for reporting. In most cases the size of the "small volume of tissue" (perhaps $1 \mathrm{~mm}^{3}$ for microstructures such as the optic chiasm or cochlea and $100 \mathrm{~mm}^{3}$ for macrostructures such as the brainstem) and the value of the "accepted tolerance dose" remain to be defined. However, by uniformly reporting these values along with clinical outcomes, the "accepted tolerance dose" limits for these structures can be better defined based on prospective, relevant radiosurgery data. For example Mayo et al. ${ }^{45}$ provide a definition of the dose/volume limit to the optic pathway, included in QUANTEC, but their recommendation refers only to the $\mathrm{D}_{\max }$, and the authors emphasize that multiinstitutional studies with dose-volume histogram analyses are needed to examine the volumetric response.

The one point in which the current report differs from past recommendations from the ICRU is in the suggestion that maximum and minimum dose should be related to the $\mathrm{D}_{\mathrm{vol}}$ and not to the $\mathrm{D}_{\%}$. It is considered self-evident that the inconsistencies of volume evaluation (also noted above) preclude the eventual use of the $\mathrm{D}_{\%}$ in OARs.

Moving forward, target dose delivery measures and acceptable dose limit criteria will need to be applied not only for single-session (fraction) treatments but also for multiple treatments due to the growing interest and utilization of fractionation in this field. Studies investigating the significance of the number of fractions in the response to treatment and in toxicity will benefit from implementation of uniform dose reporting definitions as outlined above.

\section{New Terminology}

Two new terms have been introduced and, while it is true that nothing is fundamentally changed by a name, it is still possible to be more comprehensive, accurate, or precise. Treated Target Volume (TTV) replaces the many abbreviations for a previously unnamed parameter $\left(\mathrm{TV}_{\mathrm{PIV}}\right.$, GTV in PIV, VT $\cap$ VP, and PIVTV) with an intuitive term. The TTV refers to the volume within the target that meets or exceeds the prescription dose. Total Absorbed Energy (TAE) replaces the somewhat confusing historical term Integral Dose by correctly referring to the amount of energy (mJ) imparted to the target.

\section{Data Collection}

Central to all such studies is the recording and processing of the data. There were several comments from Society members that the requirements of the report were too complex. There are assurances from one manufacturer, Elekta Instrument AB Stockholm, that they will endeavor to modify their planning software to incorporate the recommendations of the LGKS and also to make the collection of these data simple and practical. Data assembly platforms being developed, such as the Gamma Knife Registry, will enable sharing of this improved quality information between centers. These registries need to include a complete record of treatment parameters to allow accurate retrospective analyses of patient treatments and, again, agreement on a uniform terminology is essential.

\section{Implementation and Revision}

This report, having been agreed upon, now requires implementation, audit, and periodic reassessment. Implementation will be tested within the Society. Abstracts and presentations to the LGKS will be expected to adhere to the recommendations. It is suggested that acknowledgment of standards in written publications be indicated by a footnote to the Methods section or its equivalent, to read as follows: "Methods, definitions, and units conform to the standards recommended by the International Leksell Gamma Knife® Society, except where specifically noted.”

\section{Conclusions}

An agreement has been achieved, by a majority vote in the LGKS, to adhere to standard radiosurgery terminology. The series of recommendations relates only to nomenclature and is not prescriptive with regard to methods of treatment. It is hoped that this will lead to closer agreement across technologies in radiosurgery.

This first standardization report identifies inconsistencies in terminology and summarizes recommendations for volume definition and dosimetry in radiosurgery that now complement the ICRU standard terminology without losing any existing advantages identified by Gamma Knife users. It identifies a number of requirements that are common to radiosurgery (not only to Gamma Knife surgery), and examples of the more important of these are as follows:

1. The need for all to use the same terminology-for example, Prescription Dose and not peripheral, planning, or marginal dose.

2. The need to introduce and use the concept of Absorbed Dose as well as Prescription Dose.

3. The need to consolidate the concept of a Treated Target Volume, which is important for monitoring the quality of planning. 
4. The need when considering Accepted Tolerance Dose to Organs at Risk (OARs) to use the dose to a specific volume (and not the percentage [\%] of volume as indicated by the ICRU).

The Discussion section reconsiders variability in target definition and the evident need for a contouring consensus. The presence of geometrical uncertainties and target movement, in particular with noninvasive immobilization and fractionated treatment approaches, may require the appropriate introduction of more traditional ICRU terminology including the term Planning Target Volume (PTV). The necessity to reevaluate and define the importance of indexes of planning quality is emphasized. The requirement for a more coordinated and accurate measurement of dose to structures and organs at risk (OARs) is identified. All of these areas require that an improved terminology be agreed upon and implemented.

An agreed-upon and uniform nomenclature and subsequent standardization of certain methods and procedures will advance the clinical science of stereotactic radiosurgery.

\section{Disclosure}

The cost of the LGKS Internet ballot was reimbursed by Elekta AB Stockholm. Dr. Larson declares direct stock ownership in American Shared Hospital Services and is a consultant to Medical Radiation Centers. Drs. Lindquist and Novotny are consultants with Elekta Instrument AB. Drs. Lippitz and Paddick are also consultants to Elekta AB.

Author contributions to the study and manuscript preparation include the following. Conception and design: Torrens, C Chung, HT Chung, Jaffray, Kemeny, Lippitz, Novotny, Paddick. Acquisition of data: Torrens, Hanssens, Paddick. Analysis and interpretation of data: Torrens, HT Chung, Lippitz, Paddick. Drafting the article: Torrens, C Chung, HT Chung, Jaffray, Kemeny, Levivier, Lippitz, Paddick, Yu. Critically revising the article: all authors.

\section{References}

1. American College of Radiology: ACR-ASTRO Practice Guideline for the Performance of Stereotactic Radiosurgery. (http://www.acr.org/ /media/F80A2737FF0F4753B6AB ABA73E15D757.pdf) [Accessed August 6, 2014]

2. Arn T, Carlsson P: Deflection of a head fixated in a stereotactic frame with insulated posts. World Science. (http://www. world-sci.com/read.aspx?id=568) [Accessed August 6, 2014]

3. Barnett GH, Linskey ME, Adler JR, Cozzens JW, Friedman WA, Heilbrun MP, et al: Stereotactic radiosurgery-an organized neurosurgery-sanctioned definition. J Neurosurg 106: $1-5,2007$

4. Bednarz G, Downes MB, Corn BW, Curran WJ, Goldman HW: Evaluation of the spatial accuracy of magnetic resonance imaging-based stereotactic target localization for gamma knife radiosurgery of functional disorders. Neurosurgery 45:11561163,1999

5. Beegle RD, Friedman WA, Bova FJ: Effect of treatment plan quality on outcomes after radiosurgery for vestibular schwannoma. J Neurosurg 107:913-916, 2007

6. Benedict SH, Yenice KM, Followill D, Galvin JM, Hinson W, Kavanagh B, et al: Stereotactic body radiation therapy: the report of AAPM Task Group 101. Med Phys 37:4078-4101, 2010 (Erratum in Med Phys 39:563, 2012)

7. Borden JA, Mahajan A, Tsai JS: A quality factor to compare the dosimetry of gamma knife radiosurgery and intensity-modulated radiation therapy quantitatively as a function of target volume and shape. Technical note. J Neurosurg 93 Suppl 3: 228-232, 2000

8. Buis DR, Lagerwaard FJ, Barkhof F, Dirven CM, Lycklama GJ, Meijer OW, et al: Stereotactic radiosurgery for brain AVMs: role of interobserver variation in target definition on digital subtraction angiography. Int J Radiat Oncol Biol Phys 62:246-252, 2005

9. Chang SD, Main W, Martin DP, Gibbs IC, Heilbrun MP: An analysis of the accuracy of the CyberKnife: a robotic frameless stereotactic radiosurgical system. Neurosurgery 52:140-147, 2003

10. Cohen DS, Lustgarten JH, Miller E, Khandji AG, Goodman RR: Effects of coregistration of MR to CT images on MR stereotactic accuracy. J Neurosurg 82:772-779, 1995

11. Daisne JF, Sibomana M, Bol A, Cosnard G, Lonneux M, Grégoire V: Evaluation of a multimodality image (CT, MRI and PET) coregistration procedure on phantom and head and neck cancer patients: accuracy, reproducibility and consistency. Radiother Oncol 69:237-245, 2003

12. DiBiase SJ, Kwok Y, Yovino S, Arena C, Naqvi S, Temple R, et al: Factors predicting local tumor control after gamma knife stereotactic radiosurgery for benign intracranial meningiomas. Int J Radiat Oncol Biol Phys 60:1515-1519, 2004

13. Do L, Pezner R, Radany E, Liu A, Staud C, Badie B: Resection followed by stereotactic radiosurgery to resection cavity for intracranial metastases. Int J Radiat Oncol Biol Phys 73: 486-491, 2009

14. Feigl GC, Pistracher K, Berghold A, Mokry M: Pituitary insufficiency as a side effect after radiosurgery for pituitary adenomas: the role of the hypothalamus. Clinical article. J Neurosurg 113 Suppl:153-159, 2010

15. Flickinger JC, Kondziolka D, Lunsford LD, Kassam A, Phuong LK, Liscak R, et al: Development of a model to predict permanent symptomatic postradiosurgery injury for arteriovenous malformation patients. Int J Radiat Oncol Biol Phys 46:1143-1148, 2000

16. Flickinger JC, Kondziolka D, Pollock BE, Maitz AH, Lunsford LD: Complications from arteriovenous malformation radiosurgery: multivariate analysis and risk modeling. Int J Radiat Oncol Biol Phys 38:485-490, 1997

17. Friedman WA, Bova FJ, Bollampally S, Bradshaw P: Analysis of factors predictive of success or complications in arteriovenous malformation radiosurgery. Neurosurgery 52:296-308, 2003

18. Gevaert T, Levivier M, Lacornerie T, Verellen D, Engels B, Reynaert N, et al: Dosimetric comparison of different treatment modalities for stereotactic radiosurgery of arteriovenous malformations and acoustic neuromas. Radiother Oncol 106: 192-197, 2013

19. Grégoire V, Mackie TR: Dose and volume specification for reporting radiation therapy: summary of the proposals of the ICRU report committee on conformal therapy and IMRT with photon beams, in Dose Reporting in Ion Beam Therapy. Proceedings of a meeting Organized Jointly by the International Atomic Energy Agency and the International Commission on Radiation Units and Measurements, Inc. and Held in Ohio, United States of America, 18-20 March 2006. Vienna: International Atomic Energy Agency, 2007, pp $117-122$

20. Hayhurst C, Monsalves E, Bernstein M, Gentili F, Heydarian M, Tsao M, et al: Predicting nonauditory adverse radiation effects following radiosurgery for vestibular schwannoma: a volume and dosimetric analysis. Int J Radiat Oncol Biol Phys 82:2041-2046, 2012

21. Heck B, Jess-Hempen A, Kreiner HJ, Schöpgens H, Mack A: Accuracy and stability of positioning in radiosurgery: longterm results of the Gamma Knife system. Med Phys 34:14871495,2007

22. International Commission on Radiation Units and Measure- 
ments: ICRU Report 62. Prescribing, Recording and Reporting Photon Beam Therapy (Supplement to ICRU report 50). Bethesda, MD: ICRU, 1999

23. Karger CP, Jäkel O, Debus J, Kuhn S, Hartmann GH: Threedimensional accuracy and interfractional reproducibility of patient fixation and positioning using a stereotactic head mask system. Int J Radiat Oncol Biol Phys 49:1493-1504, 2001

24. Karlsson B, Kalend A, Martinez R: Frame stability and anatomical QA in radiosurgery. Acta Neurochir (Wien) 153: 2265-2270, 2011

25. Kataria T, Gupta D, Karrthick KP, Bisht SS, Goyal S, Abhishek A, et al: Frame-based radiosurgery: is it relevant in the era of IGRT? Neurol India 61:277-281, 2013

26. Ken S, Di Gennaro G, Giulietti G, Sebastiano F, De Carli D, Garreffa G, et al: Quantitative evaluation for brain CT/MRI coregistration based on maximization of mutual information in patients with focal epilepsy investigated with subdural electrodes. Magn Reson Imaging 25:883-888, 2007

27. Klein EE, Hanley J, Bayouth J, Yin FF, Simon W, Dresser S, et al: Task Group 142 report: quality assurance of medical accelerators. Med Phys 36:4197-4212, 2009

28. Korytko T, Radivoyevitch T, Colussi V, Wessels BW, Pillai K, Maciunas RJ, et al: 12 Gy gamma knife radiosurgical volume is a predictor for radiation necrosis in non-AVM intracranial tumors. Int J Radiat Oncol Biol Phys 64:419-424, 2006

29. Kreil W, Luggin J, Fuchs I, Weigl V, Eustacchio S, Papaefthymiou G: Long term experience of gamma knife radiosurgery for benign skull base meningiomas. J Neurol Neurosurg Psychiatry 76:1425-1430, 2005

30. Larson DA, Bova F, Eisert D, Kline R, Loeffler J, Lutz W, et al: Consensus statement on stereotactic radiosurgery quality improvement. The American Society for Therapeutic Radiology and Oncology, Task Force on Stereotactic Radiosurgery and the American Association of Neurological Surgeons, Task Force on Stereotactic Radiosurgery. Int J Radiat Oncol Biol Phys 28:527-530, 1994

31. Leksell Gamma Knife Society: Leksell Gamma Knife: Indications Treated 1991 to 2012, 68\%-100\% of Sites Reporting. Stockholm: Leksell Gamma Knife Society, 2013

32. Leksell L: Stereotactic radiosurgery. J Neurol Neurosurg Psychiatry 46:797-803, 1983

33. Linskey ME, Johnstone PAS: Radiation tolerance of normal temporal bone structures: implications for gamma knife stereotactic radiosurgery. Int J Radiat Oncol Biol Phys 57:196200, 2003

34. Liscák R, Novotný J Jr, UrgoSik D, Vladyka V, Simonová G: Statistical analysis of risk factors after gamma knife radiosurgery of acoustic neurinomas, in Kondziolka D (ed): Radiosurgery 1999. 4th International Stereotactic Radiosurgery Society Meeting, Sydney, February 1999. Basel: Karger, 2000, Vol 3, pp 205-213

35. Lunsford LD, Alexander E, Chapman P, Coffey R, Friedman W, Harsh G IV, et al: Consensus statement on stereotactic radiosurgery: quality improvement. Neurosurgery 34:193-195, 1994

36. Ma L, Sahgal A, Nie K, Hwang A, Karotki A, Wang B, et al: Reliability of contour-based volume calculation for radiosurgery. Laboratory investigation. J Neurosurg 117 Suppl: 203-210, 2012

37. Maciunas RJ, Galloway RL Jr, Latimer JW: The application accuracy of stereotactic frames. Neurosurgery 35:682-695, 1994

38. Mack A, Czempiel H, Kreiner HJ, Dürr G, Wowra B: Quality assurance in stereotactic space. A system test for verifying the accuracy of aim in radiosurgery. Med Phys 29:561-568, 2002

39. Maes F, Collignon A, Vandermeulen D, Marchal G, Suetens P: Multimodality image registration by maximization of mutual information. IEEE Trans Med Imaging 16:187-198, 1997

40. Marek J, Jezková J, Hána V, Krsek M, Bandúrová L, Pecen L, et al: Is it possible to avoid hypopituitarism after irradiation of pituitary adenomas by the Leksell gamma knife? Eur J Endocrinol 164:169-178, 2011

41. Marks LB, Ten Haken RK, Martel MK (eds): Quantitative Analyses of Normal Tissue Effects in the Clinic (QUANTEC). Int J Radiat Oncol Biol Phys 76 (3 Suppl):S1-S160, 2010

42. Masi L, Casamassima F, Polli C, Menichelli C, Bonucci I, Cavedon $\mathrm{C}$ : Cone beam $\mathrm{CT}$ image guidance for intracranial stereotactic treatments: comparison with a frame guided set-up. Int J Radiat Oncol Biol Phys 71:926-933, 2008

43. Massager N, Abeloos L, Devriendt D, Op de Beeck M, Levivier M: Clinical evaluation of targeting accuracy of gamma knife radiosurgery in trigeminal neuralgia. Int J Radiat Oncol Biol Phys 69:1514-1520, 2007

44. Massager N, Lonneville S, Delbrouck C, Benmebarek N, Desmedt F, Devriendt D: Dosimetric and clinical analysis of spatial distribution of the radiation dose in gamma knife radiosurgery for vestibular schwannoma. Int J Radiat Oncol Biol Phys 81:e511-e518, 2011

45. Mayo C, Martel MK, Marks LB, Flickinger J, Nam J, Kirkpatrick J: Radiation dose-volume effects of optic nerves and chiasm. Int J Radiat Oncol Biol Phys 76 (3 Suppl):S28-S35, 2010

46. Mitine C, Gilbeau L, Dessy F, Rooijackkers H, Pirson C, Rosier J, et al: Fractionated stereotactic radiotherapy of base of skull meningiomas: a preliminary comparison in the delineation of the gross tumor volume between four medical specialities, in Kondziolka D (ed): Radiosurgery. 7th International Stereotactic Radiosurgery Society Meeting, Brussels, September 2005. Basel: Karger, 2006, Vol 6, pp 131-139

47. Nakamura JL, Verhey LJ, Smith V, Petti PL, Lamborn KR, Larson DA, et al: Dose conformity of gamma knife radiosurgery and risk factors for complications. Int J Radiat Oncol Biol Phys 51:1313-1319, 2001

48. Paddick I: A simple scoring ratio to index the conformity of radiosurgical treatment plans. Technical note. J Neurosurg 93 Suppl 3:219-222, 2000

49. Paddick I, Lippitz B: A simple dose gradient measurement tool to complement the conformity index. J Neurosurg 105 Suppl:194-201, 2006

50. Petti PL, Kunwar S, Larson DA: A theoretical investigation of optimal target-dose conformity in gamma knife radiosurgery. Med Phys 38:2812-2819, 2011

51. Rowshanfarzad P, Sabet M, O'Connor DJ, Greer PB: Isocenter verification for linac-based stereotactic radiation therapy: review of principles and techniques. J Appl Clin Med Phys 12:3645, 2011

52. Ruschin M, Nayebi N, Carlsson P, Brown K, Tamerou M, Li $\mathrm{W}$, et al: Performance of a novel repositioning head frame for gamma knife perfexion and image-guided linac-based intracranial stereotactic radiotherapy. Int J Radiat Oncol Biol Phys 78:306-313, 2010

53. Sajeev T, Sampath S, Indiradevi B, Bhanumathy G, Supe SS, Musthafa MM: A novel technique to evaluate the geometrical accuracy of CT-MR image fusion in Gamma Knife radiosurgery procedures. Pol J Med Phys Eng 16:55-66, 2010

54. Sandstrom H: Variability in Target Delineation in Stereotactic Radiosurgery With Leksell Gamma Knife Perfexion and a Perspective on Radiobiological Outcome: A Multiobserver Study [master's thesis]. Stockholm: Stockholm University, 2011

55. Schlesinger D, Xu Z, Taylor F, Yen CP, Sheehan J: Interfraction and intrafraction performance of the Gamma Knife Extend system for patient positioning and immobilization. Clinical article. J Neurosurg 117 Suppl:217-224, 2012

56. Shaw E, Kline R, Gillin M, Souhami L, Hirschfeld A, Dinapoli R, et al: Radiation Therapy Oncology Group: radiosurgery quality assurance guidelines. Int J Radiat Oncol Biol Phys 27:1231-1239, 1993 


\section{Standardization in radiosurgery}

57. Sidhu K, Cooper P, Ramani R, Schwartz M, Franssen E, Davey P: Delineation of brain metastases on $\mathrm{CT}$ images for planning radiosurgery: concerns regarding accuracy. Br J Radiol 77: 39-42, 2004

58. Tao JX, Hawes-Ebersole S, Baldwin M, Shah S, Erickson RK, Ebersole JS: The accuracy and reliability of 3D CT/MRI coregistration in planning epilepsy surgery. Clin Neurophysiol 120:748-753, 2009

59. Tonetti D, Bhatnagar J, Lunsford LD: Quantitative analysis of movement of a cervical target during stereotactic radiosurgery using the Leksell Gamma Knife Perfexion. Laboratory investigation. J Neurosurg 117 Suppl:211-216, 2012

60. van de Langenberg R, de Bondt BJ, Nelemans PJ, Baumert BG, Stokroos RJ: Follow-up assessment of vestibular schwannomas: volume quantification versus two-dimensional measurements. Neuroradiology 51:517-524, 2009

61. Woo HJ, Hwang SK, Park SH, Hwang JH, Hamm IS: Factors related to the local treatment failure of gamma knife surgery for metastatic brain tumors. Acta Neurochir (Wien) 152: 1909-1914, 2010

62. 4. Definition of volumes. J ICRU 10:41-53, 2010

Manuscript submitted May 30, 2014.

Accepted July 25, 2014.

Portions of this work were presented as proceedings at the 16th International Leksell Gamma Knife Society Meeting in Sydney, Australia, March 26-29, 2012.

Please include this information when citing this paper: DOI: 10.3171/2014.7.GKS141199.

Address correspondence to: Michael Torrens, F.R.C.S., Department of Neurosurgery, Hygeia Hospital, 4 Erythrou Stavrou, Maroussi, 15123 Athens, Greece. email:m.torrens@hygeia.gr. 